\title{
Agile and generic work values of British vs Indian IT workers: a culture-clash case
}

\author{
Carla A.J. Bastiaansen and Celeste P.M. Wilderom \\ University of Twente, Enschede, The Netherlands
}

Work values of cross-cultural IT workers

\begin{abstract}
Purpose - After deciding to become agile, many information technology (IT) units struggle; they underestimate the needed managerial expertise to alter their current culture toward an agile one, particularly when cross-cultural (f)actors are involved. Given that work values are the key to an organizational culture, the study derived a set of agile work values of culturally diverse IT professionals together with a set of well-known generic work values. Consequently, the authors illustrate that managers in charge of the transition to an effective agile culture must pay serious attention to the specific value constellations of its often highly diverse workforce.

Design/methodology/approach - A literature review resulted in an initial list of agile work values. Then, mainly through a Delphi round, 12 agile-specific work values were established. These were survey rated, along with the validated set of 18 generic work values, by 102 British and Indian IT professionals in a digital service and consulting firm that was requested by its client to become agile. The observations made in 14 feedback group-interview-type dialogs enriched the surveyed data further.

Findings - In the current exploratory study, four generic value dimensions were complemented by two agilespecific ones: team communication and shared responsibility. Among the British and Indian (on-site and offshore) workers, only 2 of the 30 current work values were shared while 7 significant value differences were found, explaining the noted employee bitterness, productivity losses and client disengagement. This situation was reflected in the many discrepancies between the professionals' ideal agile way of working and how their unit was currently functioning.

Originality/value - The multi-method study shows an over-optimistic approach to becoming agile in a common cross-cultural context; insights are gained on how to optimize agile ways of organizing IT work when British IT workers collaborate with Indian IT workers. It may benefit many agile practitioners and managers working with(in) cross-culturally mixed and partly remote teams.
\end{abstract}

Keywords Agile work values, Agile transformation, Agile culture, British and Indian IT employees

Paper type Research paper

\section{Introduction}

As the global coronavirus (COVID-19) crisis has forced many organizations to act with unaccustomed speed, becoming more agile is widely assumed a necessity to remain competitive or relevant (Denning, 2020; Janssen and Van der Voort, 2020). The agile way of working is a "game-changing" strategy aimed at fast innovations and is, therefore, being embraced by the C-Suite of many leading firms such as Apple, Microsoft and Amazon that use the agile Scrum methodology [1] "by the book" (Denning, 2019, 2020; Dikert et al., 2016; Magistretti et al., 2019). Both their financial results and employee engagement scores have increased spectacularly (Denning, 2019) [2]. Changing employee mindsets from conventional ways of working is often underestimated; it is not a knob that can be switched swiftly. Hence, not all agile-adopting work units are doing so well

(C) Carla A.J. Bastiaansen and Celeste P.M. Wilderom. Published by Emerald Publishing Limited. This article is published under the Creative Commons Attribution (CC BY 4.0) licence. Anyone may reproduce, distribute, translate and create derivative works of this article (for both commercial and noncommercial purposes), subject to full attribution to the original publication and authors. The full terms of this licence may be seen at http://creativecommons.org/licences/by/4.0/legalcode 
JSMA

15,3

(Balasubramaniam et al., 2017; Denning, 2018, 2019; Dikert et al., 2016; Gandomani and Nafchi, 2016; Gregory et al., 2016; Gupta et al., 2019). Many of them face the highest-ranked persisting problem associated with an agile changeover: culture (Digital.ai ${ }^{\text {TM }}$, 2020). In part, managing agility is complex due to the presence of cross-culturally diverse employees working remotely (Smite et al., 2021; Thorgren and Caimain, 2019). Plus, academic culture studies on becoming an effective agile work unit, including the values underlying employee behaviors, have been largely overlooked by most agile research conducted thus far (Pacheco et al., 2016): Hence, it is the topic of this paper.

Western corporations often look to Indian employees to scale digital work (Šmite et al., 2021). The Republic of India, with low labor costs, is world leading in Digital information technology (IT) Services and Business Process Outsourcing, with the industry's revenue estimated at US\$194 bn in FY2021 (IBEF, 2021). Western firms have multiple reasons to continue offshoring IT work, including the scarcity of IT talent in the Western market, scaling for rapid digital growth and increasing their productivity and business value (Gregory et al., 2016; Taponen and Kauppi, 2020). Lately, Indian and other IT and outsourcing firms have begun transitioning to an agile way of working, thereby sequencing from a traditionally managed service model to agile managed services [3] (Gewald and Schäfer, 2017). From a historical perspective, the Indian managed services [4] market was established by large organizations in the United Kingdom (UK), with Europe tending to follow (Whitelane Research and PA Consulting Group, 2018). Therefore, the UK is a natural place for agile culture research. To date, hardly any studies have reported on the complex cultural issues involved in establishing an effective agile workforce. New studies would need to be of practical relevance to the many managers who are currently implementing agile ways of working, often in cross-cultural contexts. The basic research question addressed by this paper is, therefore, as follows: What workvalue differences are involved among culturally diverse IT personnel during their unit's transition to an effective agile organizational culture, and what does that mean for managing this transition well?

Our exploratory empirical study has been divided into three parts, with corresponding sub-questions, and offers insights into how to measure an agile work culture and into how complex agile workforces collaborate when people from very different national cultures join forces, especially those with British and Indian identities. The contributions of the research include (1) insights into the underlying set of generic work values in (aspiring) agile work settings; (2) the empirical discovery of two specific work values that have not been considered before in prior agility research; (3) the ranking of agile work values among a culturally diverse group of IT workers (Indian and British IT ones: onshore and offshore) and (4) an illustrative exploration of the managerial issues acting as barriers within an Indian IT-firm unit that had been requested by its one large UK client to transition to an agile way of working.

In what follows, we first review the extant topical literature, after which our exploratory field-research methods and results are presented, followed by the theoretical and practical implications and then the conclusions.

\section{Literature review}

One of the biggest challenges in our Volatile, Uncertain, Complex and Ambiguous (VUCA) world is establishing organizational cultures so that the people become effectively engaged, foster needed innovations and develop dynamic capabilities to address variations in their environment and thereby remain relevant (Achtenhagen et al., 2013; Felipe et al., 2017; Ilmudeen et al., 2021; Jafra-Sadeghi et al., 2022; Trabucchi et al., 2020; Walter, 2021). Agile ways of working are heralded to this end (Jafra-Sadeghi et al., 2022). Yet, obviously, 
agility can only be of help if it is implemented effectively. An effective fully agile organization has to adapt and respond on time and in responsible ways, given its continuously changing particular environments, so as to survive and thrive (Felipe et al., 2017; Ilmudeen et al., 2021; Janssen and Van der Voort, 2020). When transitioning toward an effective agile way of working, IT firms or units face considerable barriers that tend to be of a cultural nature (Balasubramaniam et al., 2017; Smite et al., 2021; Tolfo et al., 2011).

\subsection{Doing or being agile?}

Start-up organizations, like Spotify and Netflix, were born with agile principles and grew an even more mature agile mindset over time (Beecham et al., 2021; Denning, 2018; Rigby et al., 2018). Many other already established firms, like Amazon, Internationale Nederlanden Group, a.s.r. and Ericsson, are transitioning from traditional hierarchies to agile enterprises (Paasivaara et al., 2018; Rigby et al., 2018). In smaller organizations, IT workers often initiate an agile project, which is inspired by the "agile philosophy" of the Agile Manifesto for Agile Software Development (Beck et al., 2001; Conforto et al., 2014). They then use agile methods and tools to do their work (Paasivaara et al., 2018).

Scrum is the most widely practiced agile method and some organizations mix Scrum elements with other methods to build their own so-called home-grown approaches (Bianchi et al., 2020; Digital.ai ${ }^{\text {TM }}$, 2020; Dikert et al., 2016; Gregory et al., 2016). Agile ways of working usually encompass teams breaking their work into tasks and setting goals that can be completed within relatively short time-boxed iteration cycles, called sprints, of commonly two weeks. Collaborating in such a sprint work-cycle is positively related to product quality (Bianchi et al., 2020). Team collaboration is also supported by the most recommended agile project management tool, "Atlassian Jira board" (Beecham et al., 2021; Digital.ai ${ }^{\mathrm{TM}}$, 2020). However, "doing agile" typically does not yield the desired consistent or effective agile culture, even when supported by agile tools and methods. It needs a particular agile mindset to be shared among all the culturally alike employees (Denning, 2019; Dikert et al., 2016; Tolfo et al., 2011). Therefore, a large unwanted and potentially costly gap often exists between "doing agile" and "being an effective agile culture" (Figure 1).

Humans, and every group of collaborating workers, have values. Values are "desirable, trans-situational goals, varying in importance, that serve as guiding principles in people's lives" (Schwarz, 1996, p. 2). They form the largely invisible essence of their "culture." "Values determine the definition of 'good' and 'bad' of norms and are therefore closely related to the ideals shared by the group" (Trompenaars and Hampden-Turner, 2012, p. 30; Schein, 1985). Work values direct employees' attitudes, norms and behaviors, plus aid in handling strategic objectives, business ethics and decision-making by leaders (Baek et al., 2019; Brown and Treviňo, 2009; Fagerholm and Pagels, 2014; Nowak, 2020; Schwartz, 2012; Sharma, 2015). Hence, the behaviors and perceptions of people working in any group tend to be anchored in their work values (Denning, 2020; Rigby et al., 2018). Nevertheless, even though the methods/tools used in agile work settings are based on the workers' work values, the mere use of those methods does not simply ingrain these values into the employees working mindset (Denning, 2020; Dikert et al., 2016; Felipe et al., 2017; Livari and Livari, 2011; Pellizzoni et al., 2019).

Based on the current agile literature, a desirable agile work culture does not automatically come with the dynamic capability, readiness and operational competence to sense and react rapidly and responsibly to expected and occurring changes in the clients' environments and changed conditions (Felipe et al., 2017; Ilmudeen et al., 2021; Janssen and Van der Voort, 2020; Teece, 2007). Its members must have a matching mindset to demonstrate behaviors that have a positive impact on the culture's resolve to survive in volatile environments (Felipe et al., 2017; Imuldeen et al., 2021). Systematic studies of such mindsets and their underlying (agile)
Work values of cross-cultural IT workers 
JSMA

15,3

\section{6}

Figure 1.

Towards effective agile behaviors

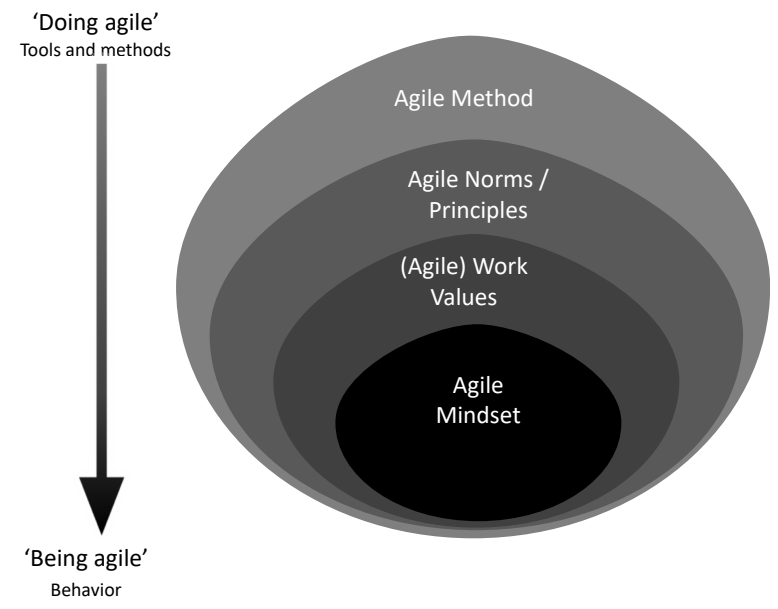

values are still rare (Denning, 2019). Also, because human-related challenges tend to impede agile transitions, Gandomani and Nafchi (2016) voiced the need for a quantitative study of agile organizational cultures. They and other authors reason that once an IT professional understands the agile values he/she will understand better why a changeover to becoming fully agile is being done and will feel more motivated to adapt to the new ways of working (Dikert et al., 2016). Workers who have adopted agile values have, indeed, been reported as collaborating more effectively and as adapting more quickly to increasingly dynamic marketplaces or environments (Felipe et al., 2017; Rigby et al., 2018). However, thus far, no well-founded specification exists of the key work values that need to be "in place" for any agile work culture to be or become effective.

\subsection{Generic and agile work values}

To explore empirically how to shape an agile mindset, Schwartz' universal or generic work values can be used as a valid baseline. His well-known four value clusters are as follows: "openness to change," "self-transcendence," "conservative" and "self-enhancement") (Brown and Treviňo, 2009; Fagerholm and Pagels, 2014; Van Dun and Wilderom, 2016). We wondered which additional agile-specific work values must be endorsed by IT workers in their process to become more effectively agile. To this effect, our research aimed to first specify a range of work values to, ultimately, support IT workers and their units with an agile mindset consistent with being effectively agile, in addition to "doing agile." This is because our search through the agile-organizational literature did not bring out a specification of an agile culture within transitioning organizations (e.g. Mathew and Taylor, 2019; Šmite et al., 2020; Śmite et al., 2021; Tolfo et al., 2011). It did show, however, the need for a more thorough and systematic examination of the human sides of supposedly agile work cultures. Hence, the first sub-question of our study is as follows: How can an agile organizational culture be operationalized in terms of work values? Before we offer an empirical answer to this question, we will first review the literature on the cross-cultural differences often found in agile settings where IT professionals collaborate, resulting in two related sub-questions to be addressed herein as well.

\subsection{How societal values may interact with agile work values?}

Cross-cultural issues often arise among employees from different countries (Beecham et al., 2021; Gupta et al., 2019; Paasivaara et al., 2018; Smite et al., 2020, 2021). Śmite et al. (2021), for 
instance, reported on alarming cultural barriers and misunderstandings between Indian employees of an Indian vendor and Swedish agile workers which impeded the success of the mature company located in Sweden. We also know, from practice, that many cultural barriers exist between British and Indian workers. Indian business organization charts, for instance, may look familiar but there are many invisible informal behavioral patterns operating in those firms based on family, caste, traditional or regional ethos, religion and other social norms (Chatterjee, 2009; Hofstede, 1991; Mathew and Taylor, 2019).

Even though very few studies exist on Indian norms and work values in distributed agile ways of working, a good exception is the research published by Balasubramaniam et al. (2017). They identified three typical Indian "scripts" which are relevant when analyzing agile ways of working: Social Hierarchy, Apane Log and Jugaad. Social Hierarchy advocates a topdown approach to decision-making and centralization of people's power over others. Apane Log refers to the importance attached to "one of us" or to affective "in-group" loyalty (Sharma, 2015). "Familiarity" and "right connections" are considered critical in organizations through reciprocal obligations such as specific mentor-mentee relationships. Jugaad implies finding non-conventional and often simplified workarounds. This involves improvisation and a trialand-error mentality (Balasubramaniam et al., 2017). While the latter script seems to be highly compatible with agile methods, Social Hierarchy is not. Therefore, we posed the sub-question 2: How much importance do British and Indian IT workers (in India and the UK) attach to generic and agile work values? Given that few IT consulting firms, or units, have culturally homogeneous labor pools, we report how IT personnel differ in terms of generic and agilespecific work values. Regarding the distributed workforce unit analyzed in this paper, which was in the process of transitioning to agile, we will report on the level of compatibility between the generic and agile work values in conjunction with Indian vs British cultural values.

There is a growing body of literature on the long-term stability and impact of societal culture values that may interact with the more common organizational values' effects on job behaviors and employees' feelings (Pacheco et al., 2016, p. 606; Thorgren and Caiman, 2019). Hence, one may view a unit's effective agile way of working as having (cross-cultural) dynamic capabilities. Each of those capabilities tends to be anchored in a set of values and norms that govern the interactions between those who collaborate in agile ways (Felipe et al., 2017). Stray et al. (2016) noted that the injunctive types of norms and principles (how people ought to behave ideally) and the descriptive norms (how behaviors come across at present) differ. Therefore, we will also address if, and how, IT workers can distinguish between current vs ideal agile ways of working. Therefore, to draw out the managerial insights from the complexities of transforming an extant digital service and consulting firm unit into a fullblown effective agile culture, sub-question 3 explores the discrepancies perceived by IT workers in their current vs the ideal agile ways of working. We first offer a brief literature review on this very question below.

\subsection{Managing the transition to being effectively agile}

Leaders have found it hard to define and instill human values throughout their enterprises when attempting to become agile (Denning, 2020; Dikert et al., 2016; Rigby et al., 2018). A literature search on agile culture confirms this: There is a focus, on the one hand, on "engagement as an attitude," intended as the capacity of individuals to generate and realize innovation and, on the other, on "engagement as involvement," which refers to co-innovation paradigms, involving both internal and external stakeholders in agile ways of working (Trabucchi et al., 2020, p. 1,460). This bifurcation may easily confound a common understanding of agile work values in relation to meaningful and productive agile work. The adoption of an effective agile mindset among employees brings many managerial challenges,
Work values of cross-cultural IT workers 
JSMA 15,3

such as handing over decision-making to self-organizing teams (Denning, 2019; Digital.ai ${ }^{\text {TM }}$, 2020; Dikert et al., 2016; Gregory et al., 2016; Gupta et al., 2019; Rebentisch et al., 2018). The entire organizational culture has to transform without a blueprint to guide it (Dikert et al., 2016; Riby et al., 2018). Hence, agile transformation must be executed with a step-by-step rhythm of iterative changes whereby the company's established hierarchical structure is gradually transformed to one that is able to embrace the agile way of working (Livari and Livari, 2011; Ŝmite et al., 2021). Magistretti et al. (2019) reported that organizations can choose to implement hybrid tactics, such as the creation of an agile unit like an agile center of excellence - dedicated to support agile implementations - without the need to restructure the overall organization/unit. At any rate, agile transformations include upskilling employees to create the conditions needed to create agile mindsets to catalyze innovations (Magistretti et al., 2019; Srinivasan and Lundqvist, 2010). Firms have considered and applied various (experimental) approaches to such a transformation. This can be achieved in combination with coaching and training the workers and/or their leaders to manage the change effectively (Gandomani and Nafchi, 2016; Paasivaara et al., 2018).

Given that few IT units start out their agile journey with a culturally homogeneous labor pool, we will report how IT professionals may differ in how they perceive the currently operating and ideal (generic and agile-specific) work values. With respect to the transitioning of the specific work unit, we analyzed these values in conjunction with Indian vs British cultural values and drew out the managerial implications. These implications are important because clients [5] are increasingly demanding highly effective agile mindsets from their IT suppliers to enhance their performance.

\section{Method}

\subsection{Design}

The field study consisted of (1) a Delphi method involving individual interviews and a focusgroup meeting with agile experts; (2) a survey among 286 IT workers of one unit of an Indian digital service and consulting firm servicing one company in the UK and this UK client demanded its IT supplier to function in agile ways; (3) focus-group discussions with the IT workers about the survey outcomes and (4) individual interviews with two of the IT firm's senior human resource (HR) managers (Figure 2).

\subsection{Interviews and Delphi}

The literature points to the importance of organizational/societal culture in relation to effective implementation of agile tools and methods but does not offer a well-founded set of agile work values yet. Hence, we first conducted eight interviews, with open-ended questions, with agile experts and thought leaders who had been involved in agile ways of working for at least 15 years at global and fore-front agile boutique consulting firms, especially financial services ones. In a subsequent group interview with 5 of them, a set of 17 agile values were derived, including a definition for each one (Table 1). To verify and consolidate them, an interview was held with one author of the original Agile Manifesto (Beck et al., 2001) after which the set was reduced to 11 agile work values. Subsequently, we explored these values through a survey. Such use of the well-known Delphi method enabled the prioritizing of the most important agile values and reaching a consensus (Gewald and Schäfer, 2017). The Delphi method has previously been shown to be suitable for "shaping a whole new discourse on organizational culture for the postmodern era" (Baek et al., 2019, p. 660).

\subsection{Survey sample and measures}

To administer the survey containing the agile-specific work values, in combination with a set of 18 earlier validated generic work values, a unit of an IT firm was approached that 


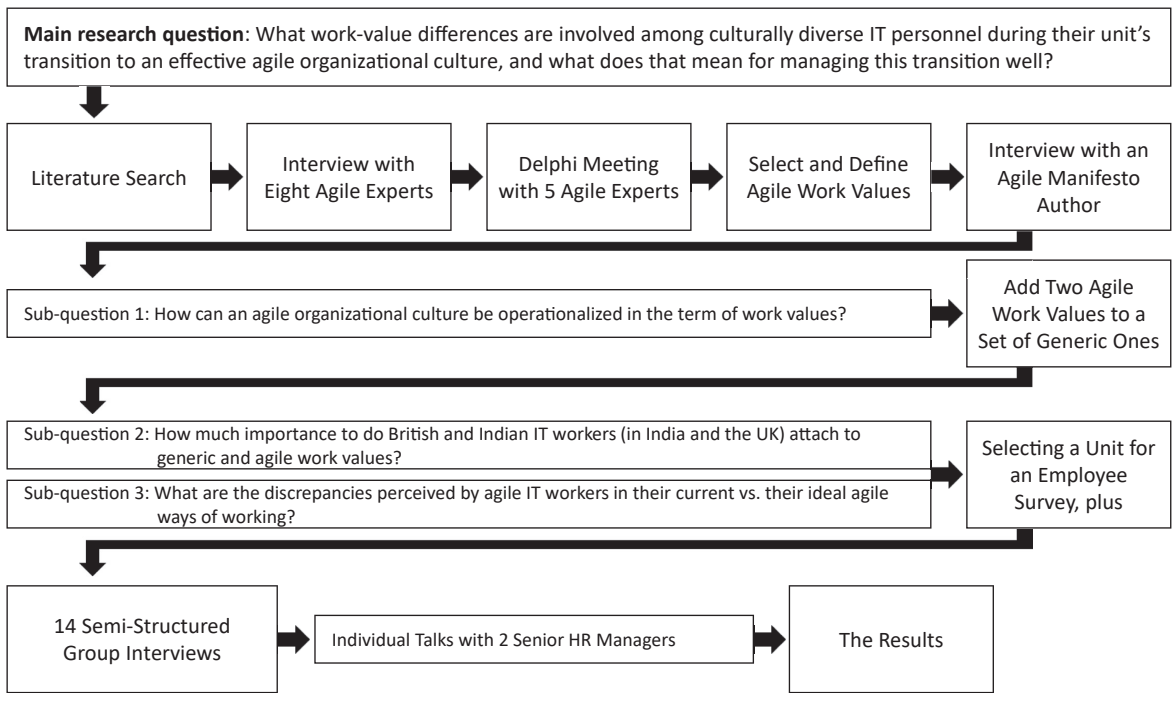

Work values of cross-cultural IT workers

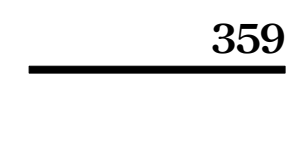

employed British and Indian nationals who did not share one integrated agile culture yet to capture the potentially different value orientations. This firm was also selected because it is one of the largest Indian established IT providers in the UK, and the UK is at the forefront of the outsourcing trend in Western countries. At the time of selecting the case unit, it had signed one of the largest managed services contracts of that year in the UK: for application maintenance and development services and related technology project management of a British subsidiary of a large European company. The British client selected this vendor because it had agreed to adapt to their organizational strategy in which agile thinking was one of the organization design principles. Thus, the focal IT unit was externally tasked to transform from traditional work methods to agile ways of working. Many other IT firms/ units are increasingly being asked by their clients to work in agile ways. We think this IT unit is a representative of workforces attempting to become agile by themselves; such a nonautonomously chosen agile-transformation strategy is unlikely to be executed well. Hence, similar contexts may benefit from the results of this study.

Five months prior to the survey, 123 British IT employees were transferred from the British client to the IT vendor's sites. The teams of this Indian-headquartered IT unit are distributed across multiple geographic locations: nearshore in the UK and offshore in India. The transferred British IT workers thus operated side-by-side with Indian-born colleagues in the UK and they also collaborated daily with "distributed" colleagues in India.

The IT company had invited the researchers to help address issues related to cultural interplay: the different work habits among the British and Indian workers. We, therefore, extended the survey to examine the current and required or ideal agile culture. The IT unit's management approached their 286 workers to complete our survey in Qualtrics: 13 Indianborn managers on-site in the UK; their 148 operational Indian offshore colleagues and the 123 transferred British IT employees. We added a randomization function to curb response bias [6].

We received 118 valid survey responses $(38.8 \%)$. Only those who had agile work experience $(n=90)$ answered the questions about the ideal agile ways of working. A total of 102 responses were useable: 71 had more than 1 year of agile work experience and 90 


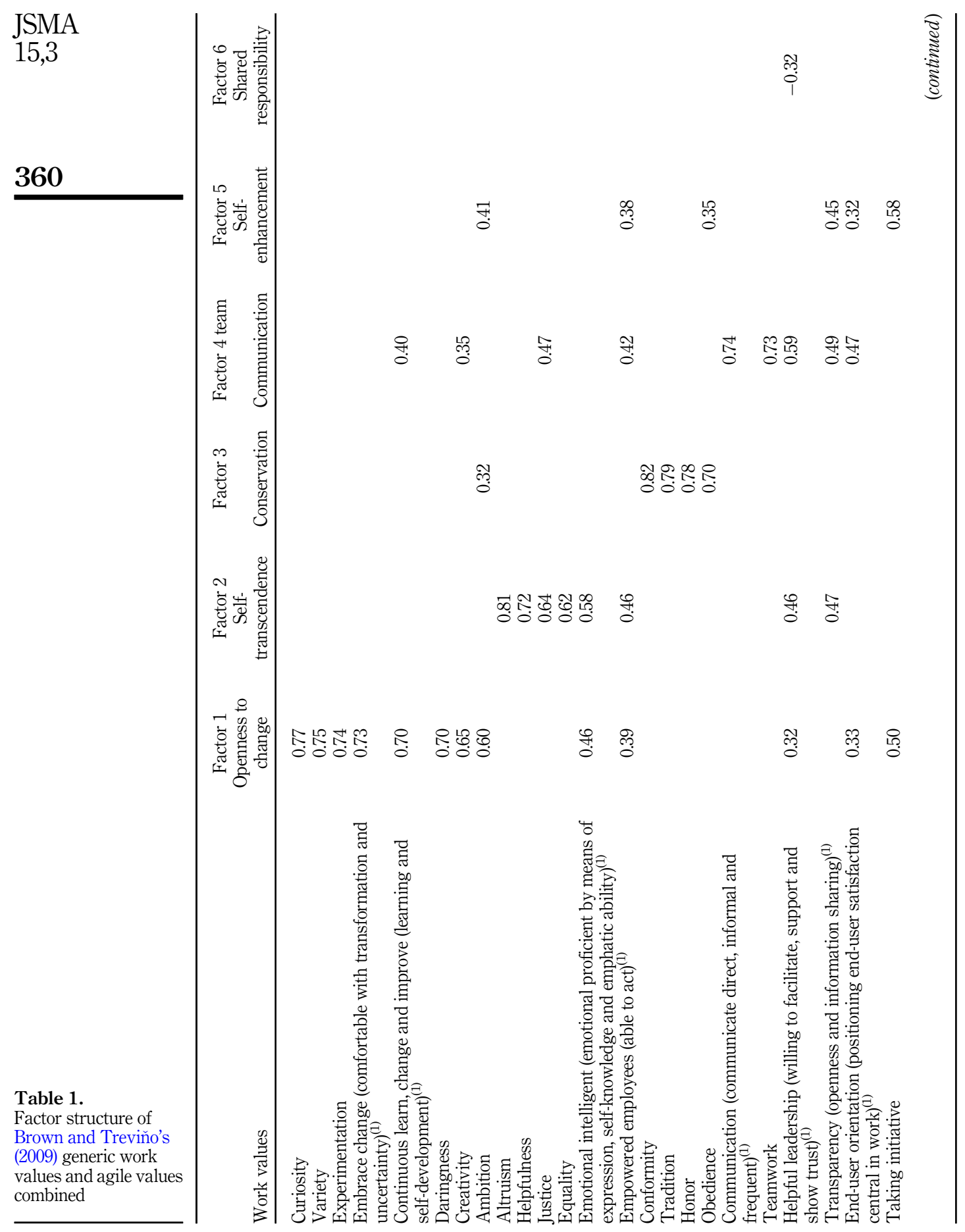


JSMA

15,3

362 respondents filled in their country of birth and country of residence. The two main survey questions were as follows: "How important are each of the 30 work values for you in your current practices?" and "Below are the same 30 work values. In an ideal agile way of working, how important should each of the work values be?"

Brown and Treviňo (2009) used Schwarz's (1996) universal values as the generic work values of those employed by a regular business organization: justice, equality, success, altruism, helpfulness, creativity, self-discipline, curiosity, variety, obedience, ambition, daringness, honor and tradition. They then added four others as follows: teamwork, experimentation, conformity and taking initiative (O'Reilly et al., 1991). Their validated 18-item measure consists of 4 sets of work values: openness to change, self-transcendence, conservative and self-enhancement. We used this measure and added the following 11 agile organizational values derived from the earlier qualitative phase of our study: fast decisionmaking based upon facts; learn, change and improve continuously; empowered employees; helpful leadership; self-organizing teamwork; shared responsibility; communication; transparency; embrace change; end-user orientation and continuous customer involvement (Table 1). Next, the list was supplemented with emotional intelligence: as a desirable teambased quality or core value of highly productive, self-organizing agile teams (Luong et al., 2019).

All the items were anchored on Brown and Treviňo's seven-point Likert scale (and Schwartz' original survey) as follows: 1: not relevant at all; 2: not important; 3: less important; 4: neutral; 5: important; 6: very important and 7: extremely important. The Kaiser-MeyerOlkin test was 0.88 and, following Bartlett's test of sphericity, $\chi^{2}(435)=1,844(p<0.001)$, indicating that the correlations among the items were high enough to perform a factor analysis. We used exploratory factor analysis with varimax rotation to validate the 30-item values measure. The results show that the four Brown and Treviño factors were replicated and that the agile values supplemented two agile factors, which we labeled as follows: Team Communication and Shared Responsibility.

\subsection{Semi-structured group interviews}

To gain a deeper understanding of the quantitative results, they were presented to the UKbased workers and discussed with them in 14 semi-structured group interviews; those on-site survey-feedback dialogs took place over two weeks with mixed groups at 2 of the UK locations. Of the 138 invited employees, 86 participated: 77 British IT workers, 7 Indian-born IT managers and 2 British IT managers. These 14 survey-feedback dialogs were captured by the researcher as notes. Based on an analysis of these notes, talks were held with the two Indian-born senior HR managers (one of whom had lived in North America and worked in various British-Indian transition projects and the other had been living in the UK for more than 20 years with similar work experience). The latter manager co-facilitated all the 14 group sessions. An advisory report was written for the IT-unit's senior management. Upon request, each survey participant received a shorter version of this report.

\section{Results}

Our findings are presented below. First, we report how all the work values had been ranked. Although most of the extant and ideal agile work values differed across the three prototypical groups - Indians on- and off-site and the British IT workers - two values were actually shared among these groups: "communication" and "helpful leadership." We interpret all the findings in terms of what they may mean for managing the transition to becoming a highly diverse effective agile IT unit. 
4.1 Most important work values

The 30 work values were first ranked by the IT workers in terms of their current importance (Table 2). Of those values, 26 were seen as important, while 7 were rated as very important: teamwork, justice, helpful leadership, communication, equality, transparency and end-user orientation; only 4 of these are specifically agile work values. The lowest-scoring (or rather neutral) values were tradition, honor, daringness and conformity.

In their current transition, all the IT unit workers managed to deal with a lot of change but it also created uncertainty. This is the backdrop against which the employees saw "helpful leadership" as highly important (rank \#3 in Table 2), and it was brought up in all the surveyfeedback dialogs. It is remarkable that the six agile experts had not noted this value at all (Table 2, last column) [7]. The IT workers felt they needed leadership support in terms of the firm's and unit's visions, other cultural guidance and performance-related information and also for their sense of belonging. The unit leaders engaged less in planning and analysis and more in Jugaad: improvisations and workarounds to reach goals (Balasubramaniam et al., 2017; Cappelli et al., 2010). The offshore IT workers in particular needed helpful leadership in the form of top-down instructions (as part of their Social Hierarchy heritage) and recognition for their results (Balasubramaniam et al., 2017; Sharma, 2015). The British workers needed a
Work values of cross-cultural IT workers

\begin{tabular}{|c|c|c|c|c|}
\hline Work values & $\begin{array}{l}102 \text { IT workers } \\
\text { Scale (1-30) }\end{array}$ & $\begin{array}{l}\text { Mean } \\
1-7^{(2)}\end{array}$ & St. dev & $\begin{array}{c}6 \text { agile experts' top } 5 \\
(1-5)\end{array}$ \\
\hline Teamwork & 1 & 6.37 & 0.78 & \\
\hline Justice & 2 & 6.33 & 0.85 & \\
\hline Helpful leadership ${ }^{(1)}$ & 3 & 6.25 & 0.93 & \\
\hline Communication $^{(1)}$ & $4-5$ & 6.20 & 1.03 & $2-3$ \\
\hline Equality & $4-5$ & 6.20 & 1.13 & \\
\hline Transparency $^{(1)}$ & 6 & 6.18 & 0.94 & 1 \\
\hline End-user orientation ${ }^{(1)}$ & 7 & 6.01 & 0.90 & 4 \\
\hline Empowered employees ${ }^{(1)}$ & 8 & 5.94 & 0.98 & $2-3$ \\
\hline Success & 9 & 5.91 & 0.90 & \\
\hline Continuous learn, change and improve ${ }^{(1)}$ & $10-11$ & 5.88 & 1.03 & \\
\hline Shared responsibility ${ }^{(1)}$ & $10-11$ & 5.88 & 1.00 & \\
\hline Altruism & 12 & 5.84 & 0.99 & \\
\hline Helpfulness & 13 & 5.79 & 1.00 & \\
\hline Creativity & 14 & 5.75 & 1.00 & \\
\hline Self-organizing teamwork ${ }^{(1)}$ & 15 & 5.70 & 1.03 & \\
\hline${\text { Embrace change } e^{(1)}}$ & 16 & 5.66 & 1.00 & \\
\hline Continuous customer involvement ${ }^{(1)}$ & 17 & 5.62 & 1.03 & \\
\hline Self-discipline & 18 & 5.60 & 1.11 & \\
\hline Taking initiative & 19 & 5.58 & 1.08 & \\
\hline Curiosity & 20 & 5.46 & 1.23 & \\
\hline Experimentation & 21 & 5.45 & 1.10 & \\
\hline Fast decision-making based upon facts ${ }^{(1)}$ & 22 & 5.43 & 0.960 & 5 \\
\hline Emotional intelligent ${ }^{(1)}$ & 23 & 5.42 & 1.06 & \\
\hline Variety & 24 & 5.35 & 1.08 & \\
\hline Obedience & 25 & 5.26 & 1.39 & \\
\hline Ambition & 26 & 5.24 & 1.17 & \\
\hline Conformity & 27 & 4.72 & 1.49 & \\
\hline Daringness & 28 & 4.52 & 1.41 & \\
\hline Honor & 29 & 4.31 & 1.59 & \\
\hline Tradition & 30 & 4.09 & 1.59 & \\
\hline
\end{tabular}

Note(s): ${ }^{(1)}$ : Agile work value; ${ }^{(2)}: 1=$ not relevant at all, $2=$ not important, $3=$ less important, $4=$ neutral, $5=$ important, $6=$ very important and $7=$ extremely important

Table 2. IT workers' and experts' importance rankings of work values 
JSMA

15,3

364

different kind of leadership; they wanted management to share more information with them, more frequent communication, and to obey British labor laws. During the survey-feedback dialogs, the Indian onshore workers appeared much less assertive about their personal needs: another cross-cultural difference.

\subsection{What current values do the three employee groups share?}

Table 3 shows that the members of all three subgroups of employees share helpfulleadership and communication as the most important values. This empirical fact was interpreted as a vote of insufficient intra-organizational communication or as an urgent employee need for more direct communication and mentoring/coaching type of leadership (Gupta et al., 2019). This was interpreted in the advisory report to the higher-level managers as a clear performance risk in the current ways of working (Beecham et al., 2021; Cappelli et al., 2010; Dikert et al., 2016; Gregory et al., 2016; Šmite et al., 2021). The British workers corroborated this insight in the qualitative part of the survey: "It is important to have sufficient face-to-face team meetings" and "We need more modern digital-conference facilities to be able to talk more often and align with colleagues located elsewhere." The HR managers then saw that more communication would lower their workers' level of anxiety (Luong et al., 2019).

Noteworthy in this context is that the agile experts had ranked fast decision-making based upon facts as highly important, while among the IT workers it ranked only \#22 (Table 2: last column). According to the agile experts and Rebentisch et al. (2018), this value typifies an important aspect of an ideal agile culture: to make decisions based on high-quality data. The fact that the average respondents ranked this value low showed that decision-making was still somehow unrelated to their own current behavior at work. The Indian managers confirmed this. Decision-making was mostly done by their Indian hierarchical leaders and hardly by the IT workers themselves. At the time of the survey, the IT unit was struggling with modernizing the client's legacy systems and timely data transfer from the client to this IT-firm's unit. Hence, the employees felt there was little relevant client data and "few facts" available to make solid decisions.

\subsection{Indian values at work}

Among the cross-culturally diverse subgroups, seven work values differed significantly (Table 3). Amidst all the Indian employees, the agile value learn, change and improve continuously was more important than for the British. Indians tend to improve and improvise (Jugaad), which brings flexibility and different, often creative, approaches to reach goals (Balasubramaniam et al., 2017). Indian IT workers tend to be stimulated at a young age to

Table 3.

Two shared and seven different importance ratings among British, on-site Indian and offshore Indian IT workers $(N=90)$

\begin{tabular}{lr}
\hline Work values & $F$-test \\
\hline Communication & 0.09 \\
Helpful leadership & 0.06 \\
Self-discipline & $15.69 * *$ \\
Conformity & $13.84^{* *}$ \\
Tradition & $12.90^{* *}$ \\
Honor & $9.36^{* *}$ \\
Continuous learn, change and improve & $7.41^{*}$ \\
End-user orientation & $6.83^{*}$ \\
Continuous customer involvement & $6.50^{*}$ \\
Note(s): Based on a 3-way ANOVA F-distribution test among the 30 (generic and agile) work values; $* p<0.05$
\end{tabular}
and $* * p<0.01$ 
become achievers, appear smart and distinguish themselves from the larger population. The best students gain access to the best universities. This developmental tendency remains with them in their working lives. Indian workers are driven to study at the IT firm's corporate university and become qualified for a job in India. These young professionals must attain high-performance levels to then become leaders while behaving according to the Apane Log script (Sharma, 2015). They are being taught that such success criteria translate into authority that can literally open Western doors for some of them.

The Indian offshore workers ranked both end-user orientation and continuous customer involvement higher than the two other groups. Likewise, the Indian workers wanted to belong more to the client's "in-groups" by making personal connections with the client's end users. This is in line with the Indian collectivistic or "we" culture (Hofstede Insights, 2021). Client opinion and loyalty are seen in India as crucial for success, jobs and income security for their extended families (Balasubramaniam et al., 2017; Hofstede Insights, 2021). However, the offshore group had no direct contact with the customer/end users. The on-site Indian managers were reluctant to reveal their lack of specific end-user understandings. Only the leadership of the IT-firm's unit was supposed to maintain communication with the client (see, also, Smite et al., 2021). Yet, the British IT workers did communicate about the end-user's needs at a lower level in the client organization. This created some tension with the on-site Indian managers, as they were not always fully informed and then needed to mediate between the British on-site workers and directions from the higher managers in India. The transferred British workers already had an end-user orientation because they had worked with the end users in their previous jobs. This means they had ample tacit knowledge about the IT unit's client and insights into the customers' whishes (which they had gained from their previous roles in the client organization). As a result, they could take high-quality service delivery as the norm and did not rate end-user orientation as being currently important. The Indian workers, on the other hand, were geared to meeting the client's requirements only after a boss explicitly requested this from them (Gupta et al., 2019). To them, respecting authority and following managers' demands appeared very important. The traditional Indian culture was still in place whereby the IT workers had to respect the traditional hierarchical work processes, i.e. in their mindset, work delivery is based on "order taking" from their managers who are supposed to be in the best position to care for the common good (Chatterjee, 2009).

Indian IT workers tend to show internal cohesive group behavior, which was also reflected in the significantly higher importance attached to the four "conservative" work values of self-discipline, conformity, tradition and honor by the Indian offshore employees. The two British-based groups scored self-discipline significantly lower. The British national culture is more permissive in that people exhibit a willingness to realize one's own impulses through a desire to enjoy life and have fun with a tendency toward optimism (Hofstede Insights, 2021). The on-site Indians seemed to have adjusted to this part of the British culture, while the offshore Indians' actions followed more fixed social norms without much behavioral indulgence.

Schwartz's conformity value refers to "fitting in" as depicted in the Apane Log script in which Indian employees also show loyalty toward their managers (Sharma, 2015) [8]. Conformity also implies following and committing to the written and unwritten rules (Brown and Treviňo, 2009). Examples are as follows: the willingness to say yes to all managerial requests; the reluctance to warn about non-feasible deadlines and working hard at odd hours (Smite et al., 2021). Those behaviors and associated values were less visible among the British workers. They took work seriously, but not too seriously (Hofstede Insights, 2021). The British workers were stunned when they received work-related calls from their team manager on Saturdays: a difference in the work-life balance among the British and Indians (Ŝmite et al., 2021; Spony, 2003). 
JSMA

15,3

366

In terms of tradition, the Indian-based employees preferred to harmonize all the extant dimensions at work (Brown and Treviño, 2009; Chatterjee, 2009). In contrast, the British IT workers tended to believe that progress comes from challenging organizational traditions and not by preserving customs (Spony, 2003). The work value honor ("showing deference to senior employees") (Brown and Treviño, 2009, p. 482) invokes the cultural script of Social Hierarchy: Indian subordinates show a great deal of deference to senior employees and perceive their work communities as "their respected family." Furthermore, "saving face" is important in any situation and that is the reason the "why" question is never asked (Balasubramaniam et al., 2017) [9]. Such types of questions may force colleagues to engage in uncomfortable explanations and thus potentially making others "lose face" (Smite et al., 2021). During the survey-feedback dialog, the British workers reacted to dilemmas with understatements and humor. To the Indian offshore workers, rituals of recognition, such as corporate certifications and awards, are of utmost importance; Oscars-like ceremonies in which highly-performing teams and individuals are recognized and rewarded are indispensable to them.

Compared to the offshore Indians, the Indians who were selected to work on-site in the UK showed a less traditional mindset. A thoughtful selection and cultural integration process abroad enables Indian-work behaviors to evolve accordingly over time (Šmite et al., 2020, 2021; Spony, 2003). The HR transition managers noted, "They seem more relaxed; working in a Western country means that the Indian employee has 'moved upwards' leading to their entire family achieving a higher social status and income." Seen over generations, most Indian families aim to move up the caste hierarchy that makes most Indians operate in statusconscious ways (Sharma, 2015).

Next to the noted current work-value differences, an organizational culture may also be typified by what it could become ideally. Given that "agile" originated as an abstract ideal method for software development, it can be seen as a "work ideology" with many different options to reach the ideal way of working. Hence, we compared this supposedly shared agile ideal to the current situation-in-transition.

\subsection{Current vs ideal agile ways of working}

Within our surveyed group of IT workers, different gaps were identified that pertained to their ideal agile values. The $t$-tests (paired difference) showed that out of the 12 assessed agile work values, 8 of them appeared to differ significantly with respect to the workers' ideal agile ways of working. Continuous customer involvement had the biggest gap (Table 4)

Table 4.

Results of current vs ideal agile work values $(N=71)$

\begin{tabular}{lccr}
\hline & Mean & & \\
Agile work values & Difference & $T$ & St. dev \\
\hline 1. Continuous customer involvement & -0.62 & $-5.43^{* * *}$ & 0.96 \\
2. Self-organizing teamwork & -0.59 & $-4.75^{* * *}$ & 1.05 \\
3. Embrace change & -0.47 & $-3.93^{* * *}$ & 1.00 \\
4. Fast decision making based upon facts & -0.37 & $-3.22^{* *}$ & 0.96 \\
5. Shared responsibility & -0.35 & $-2.53^{*}$ & 1.17 \\
6. Continuous learn, change and improve & -0.28 & $-2.60^{*}$ & 0.91 \\
7. End-user orientation & -0.27 & $-2.52^{* *}$ & 0.89 \\
8. Empowered employees & -0.25 & $-3.09^{* *}$ & 0.69 \\
9. Communication & -0.13 & -1.42 & 0.76 \\
10. Emotional intelligent & -0.11 & -1.21 & 0.79 \\
11. Transparency & -0.10 & 0.72 & -1.15 \\
12. Helpful leadership & 0.9 & 0.97 & 0.73 \\
Note(s):* $p<0.05 ; * * p<0.01$ and $* * * p<0.001$ & & & \\
\hline
\end{tabular}


(see, also, Dikert et al., 2016). Most of the surveyed workers were collaborating with the client but were not fully engaged according to their agile ideal. Only two British-born operational team managers pulled strong ownership toward themselves for the delivery of agile managed services (Paasivaara et al., 2018; Rebentisch et al., 2018), whereas their other Indian peers did not. The two British-born team managers' actions ensured that their former colleagues (who were now in their client's firm) were being served with high quality and on time. These two transferred team managers engaged proactively with their former colleagues to satisfy their client's urgent needs to "get things done" (Conforto et al., 2014). Such functioning as a semi-autonomous team was a slow-moving process for most of the other IT workers (Trabucchi et al., 2020). Fully autonomous agile teams are supposed to selforganize by taking ownership of their own developmental process and by finding a balance between their own goals and the broader organizational goals. Most of the current teams in the surveyed unit were still focused on their own tasks and goals and did not make extensive decisions at the team level (Dikert et al., 2016). Fully agile teams are supposed to be empowered to make their own decisions and be able to adapt continuously to changes in customer-relevant practices and innovations (Dikert et al., 2016; Gregory et al., 2016). Most of this IT unit's teams were not working like that yet.

Regarding the agile work value embracing change, i.e. being comfortable with agile transformations and change behaviors (Beck et al., 2001; Paasivaara et al., 2018; Rebentisch et al., 2018), the workers saw this unit as being far from ideal. For instance, the IT workers noted that in the ideal agile ways of working, the traditional split into "run" (managing daily IT) work and "change" (innovate, improve and renew IT) work does not exist. They felt that to welcome and deploy the frequent IT and business change requirements, both practices had to be integrated more. New digital technologies were needed, and the business processes had to become lean. Therefore, they voiced in all the dialog sessions that they expected many changes in their current work practices. At the same time, many of the British employees were skeptical or hesitant about this unit's new ways of working (Dikert et al., 2016); they were particularly unhappy with the limited number of allowable team meetings to coordinate the work and the lack of internal communication.

In an ideal agile way of working, decisions are made fast and are based upon facts. This agile value represented another contrast with the current ways of working. Typical behavioral indicators of this work value are a pluralistic and participative decision-making style, next to a willingness to re-assess decisions if new information comes in and trusting and enriching data. Also, employees need to feel comfortable to frequently make short-deadline decisions as well as have a mindset to use and analyze data (Rebentisch et al., 2018). Even though this agile work value seems to fit an Indian's penchant for improvisation, our surveyed Indian workers felt reluctant to expose work problems to bosses, i.e. to discuss failures, voice team criticisms or to propose alternatives to the superiors' directives (Balasubramaniam et al., 2017; Śmite et al., 2020). Moreover, the great variety of data applications and contamination during data collection and storage made it difficult for the remote workers to analyze data well and to make solid decisions based upon them. Hence, the Indian employees' Social Hierarchy script trumped Jugaad.

The survey respondents saw a significant gap between their current situation and the ideal agile value of shared responsibility in the teams; most of the workers (British and Indian) still followed the managers' instructions, which reflects the traditional centralization of accountabilities. The middle managers' new role in the ideal agile work was found to be unclear. When questioned, most of the British workers were unaware of the firm's online learning facilities. The transferred British colleagues continued their former agile ways of working. They did not ask for the IT-firm's guiding work values and preferred agile method, and the IT-firm unit did not offer it proactively (Dikert et al., 2016). The British were more inclined to learn on the job and among team members by taking the opportunities seriously to 
JSMA

15,3

368 self-improve their own tasks. This is reflected in the "is-should" gap in terms of learn, change and improve continuously (see, also, Gandomani and Nafchi, 2016).

Another "is-should" gap was regarding the agile work value end user orientation. The Indian employees wanted to gain more end user information from their transferred British colleagues. This signified a desire, on their part, to amass many useful client-business insights for their joint iterative work-development cycles. They were eager to perform well and were longing to be invited one day to meet the team and the client's end users in the UK (Dikert et al., 2016; Paasivaara et al., 2018).

In 7 of the 14 held semi-structured group interview-type dialogs with the employees, the lack of being sufficiently empowered was noted. Instead of being entrusted with decisionmaking power at the operational level, the IT workers experienced a high level of micromanagement by their management. Sufficient empowerment included participation in planning their own work projects and having the autonomy to choose their own tasks (Rebentisch et al., 2018). These issues were interpreted by the Indian higher ups as a need for more and better digital facilities. The survey results, supplemented with the qualitative feedback from the many survey respondents and the interviews with the two HR managers, were assimilated in an advisory report. This report was sent to the IT unit's senior management. The advice stressed the need for many more short-term changes.

About three months later, the UK-based employees moved to a new delivery center that was equipped with the new and needed digital workplace and collaboration space facilities. Subsequently, two months later, a roadmap was launched to accelerate the adoption of agile ways of working. This included, for example, having more face-to-face meetings, further discussions and the detailing of (agile) performance metrics and the integration of the development and operations functions (DevOps). Also, a more centrally led communication was facilitated, while some management-leader positions were shuffled, and additional UK (agile) management consultancy effort was brought in to support senior management in their agile transformation effort.

\section{Discussion}

This study operationalizes and analyzes the culture of an outsourced IT workforce in the transition phase to becoming a fully-fledged agile culture; agile and generic work values were first derived from both the literature and experts, after which the British and Indian employees were surveyed (in both quantitative and qualitative ways). This exploratory study adds two agile-value dimensions to a valid set of established generic work values. The resulting six culture dimensions and their operationalizations illustrate how British and Indian mindsets differ at work during the transformation process of an Indian-based IT unit operating for one client in the UK. In the section below, we discuss the theoretical and practical implications of the findings, the limitations as well as the resulting suggestions for future research.

\subsection{Theoretical implications}

This study sheds light on how a supposedly agile culture can be seen in terms of specific work values. Sub-question 1 was answered by extending Brown and Treviňo's (2009) 18 generic values, based on Schwartz's (1996) prior work, resulting in an exploratory factor analysis yielding two agile-specific dimensions: Team Communication and Shared Responsibility. So a first implication of this study is that the values and their six dimensions (two of which are agile specific) can be leveraged to operationalize agile work cultures. Note that although the assessed work values reside in individuals, they can be aggregated at the team and organizational (or unit) levels of analysis. 
Furthermore, the agile ways of working can be related to the dynamic capability theory. Both emphasize an organization's ability to react adequately and timely to external changes with an internal - enterprise performance-focus (Jafari-Sadeghi et al., 2022; Teece, 2007; Walter, 2021). Even though the dynamic capability theory tends to stress skills, processes, procedures, organizational structures, decision rules and/or disciplines, our agile focus was on work values, which underlines all these visible organizational phenomena. The two derived agile dimensions may contribute to seeing effective agile ways of working as possible dynamic capabilities. It would be worthwhile to link Walter's (2021) derived agility capabilities (responsiveness, competency, flexibility and speed) to the two agile-work dimensions determined herein.

Moreover, future qualitative research must examine what it would mean for individual employees in similar (supposedly) agile teams to feel they have both optimal "shared responsibility" and "team communication." Such research may lead to more insights into the best-practice agile conditions, including the managerial conditions needed for effective agileteam behaviors, especially how distributed agile workers of "low-cost countries" experience optimal shared responsibility and team communication at work and how they could achieve desirable cross-cultural adjustments.

The members of the three different groups of employees studied here felt similarly about the insufficient communication within the IT-firm unit. During the survey-feedback sessions, it was reflected that the IT unit was not unified yet in their agile ways of working. The team communications were too limited, and the employees' behaviors clashed regularly (without much noise, even though, in a few of the 14 dialogs, some crying literally took place). This undermined the morale and the trust the workers had in each other as well as the sense that they work well together. This case situation may illustrate the point that when studying a non-Western company, "cultural and regional variations [. . . can bring remarkable insights" (Ilmudeen et al., 2021, p. 523).

Given the managerial need to know more about agile and other work values in detail, we analyzed the 30 surveyed values through Balasubramaniam et al.'s (2017) lens of "cultural scripts" among Indian workers. Cultural scripts are sets of value-based expressions that are accepted in a culture as the means to influence others properly. As we have shown, it matters where IT employees and their managers are born and raised, i.e. in terms of different national values and norms (Hofstede, 1991), and we recommend future research to also examine culturally determined managerial scripts more in depth in (prospectively) agile work settings based on their (potential for changing) behavioral and associated value patterns.

\subsection{Managerial implications}

Leaders/managers of extant IT organizations who are transitioning to agile ways of working must take a critical look at the agile "communication" and "helpful leadership" work values. Both are ranked highly and are the only two values that are seen as very important among the three sub-groups studied here: the British, on-site Indian and offshore Indian IT workers. Agile ways of working need an agile mindset, which the leaders in our study still struggled with. In other words, Denning's advice (2020, p. 20) for agile leaders is applicable to them: they can add value by role-modeling agility to critical agile teams; spending more time with customers and end-users; mentoring direct reports and peers and promoting proactive value creation. Such agile coaching-like activities require more time and skills from the leaders themselves, compared to traditional managing. Thus, leaders/managers of units that become agile must empower their work-floor staff to create culturally-compatible and highlycollaborative engagement levels to build highly-productive self-organized agile teams (Beck et al., 2001; Conforto et al., 2014; Dikert et al., 2016; Pellizzoni et al., 2019; Smite et al., 2021; Srinivasan and Lundqvist, 2010; Thorgren and Caiman, 2019). Ideally, these leaders need to already role model the values to accomplish their ideal agile culture. They must communicate 
JSMA

15,3

agile whole heartedly and with humility, especially given the fact that organizational change tends to make the staff vulnerable. Shared agile team leadership still requires helpful support and subtle control from the C-Suite; they must delegate substantial decision-making authority to the agile team members as well as rewarding effective agile mindsets and instigating the much-needed psychological safety. Cross-cultural teams certainly require more managerial preparation than commonly assumed (Conforto et al., 2014; Thorgren and Caiman, 2019). Future action research may need to focus more in-depth on what "helpful leadership" and "communication" entail when (changing towards) becoming an effective agile organizational context.

\subsection{Limitations and future research}

This study was limited to a glimpse of Indian and British employees within one unit of a large Indian-IT-managed service company in the process of becoming agile. Its fine-grained results may not be generalizable, although it has often been reported (especially in the practitioneroriented literature) that IT firms or units that want to become fully or effectively agile face very similar complex challenges (e.g. Rigby et al., 2018). Future agile-culture research ought to focus on both organizational and/or unit level agile work cultures and may need to involve a wider range of national backgrounds among the IT professionals and clients, because agile work is becoming increasingly more international as are the clients, end-users and customers of agile teams.

Effective agile work settings are based on "having" an agile mindset (Denning, 2020; Dikert et al., 2016; Felipe et al., 2017; Livari and Livari, 2011). Given that, by nature, agile ways of working require a developmental organizational process, we propose that future agile transformation research designs would be enriched by longitudinal ones - by aiming to analyze the typical agile iterative approach to transform the (often cross-culturally complex) practices over a long period of time. Moreover, further agile culture studies among IT personnel must test their hypotheses with mixed-methods and multi-level research (that blends an organizational/team culture focus with a cross-cultural one) and include the roles of the client customer representatives and leaders involved.

The managerial implications may illustrate how new research on agile workforce effectiveness could benefit from the business-administrative discipline of organizational behavior. This may, for instance, include a focus on the self-transcending type of effective organizational leadership as found, for instance, in the transformational leadership style. This style seems in need of being combined with a slightly more directive, transactional or instrumental style (Hoogeboom and Wilderom, 2019). Such an extended behavioral repertoire will ensure that those workers who need more direction or support in taking own responsibilities are still guided in ways that do not clash with the other workers who do not have such needs or with those with different work-value constellations. In short, leading a group of heterogenous IT workers toward highly-effective agile teamwork can be highly demanding due to the underlying diverse cultural roots of the interacting behaviors involved; those complex and demanding job situations need much more sophisticated socio-behavioral team research. As independent teams are the lifeblood of any agile organization, it would be pertinent to focus also on the conditions of highly-effective agile teams. We must also learn more about the transformational journey of extant non-agile IT teams toward states of being a fully effective agile team or culture (Pacheo et al., 2016; Rigby et al., 2018).

\section{Conclusions and outlook}

To reap productivity gains, many digital IT companies or units are attempting to change into agile modes of working - either autonomously or prompted by external parties like their 
client(s). Transforming an existing IT work context into an agile work culture does not happen easily. We illustrate that productivity blockages can emerge when an IT company weaves agile ways of working into their extant culture. In our case, the transformation toward an agile culture was associated with very different perceptions about current and ideal ways of being agile by employees with different cultural backgrounds. We show how the roots of a productive agile work culture lie in the workers' (agile and generic) values that determine day-to-day work behaviors and their interpretations of leaders' behaviors.

Based on the agile-organizational literature, our Delphi study and the resulting factor analysis of the identified (in part agile) work values, we find that the work values can be leveraged into a reliable survey instrument for diagnosing the degree of agile-value endorsement among IT employees. Given that in some IT organizations these values and accompanying behaviors may vary from subgroup to subgroup (of employees), over time, future longitudinal, multi-level and mixed-methods studies must capture the various degrees of self-organizing agility and the related mindset (factors) of the IT employees and their managers during major (agile) transformations.

This study demonstrates that the degree of "effective agility" hinges on the maturity of the leaders' change-management skills, requiring a wholehearted embracement and role modeling of the full agile mindset along with cross-cultural skills (see, also, Denning, 2020; Gupta et al., 2019). The "very important" values associated with this mindset for IT professionals are teamwork, justice, equality, transparency, end-user orientation, helpful leadership and communication. These values mainly correspond to the two of the here examined six work-value dimensions: team communication and self-transcendence. The latter dimension is not known as being an agile-specific one. Nevertheless, it is part of the employees' mindset and offers evidence that agile ways of working are also associated with a particular set of generic work values. Moreover, the next six agile work values appeared to foster an agile employee mindset that is quite different from non-agile management assumptions: shared responsibility; learn, change and improve continuously; self-organizing teamwork; fast decision-making based upon facts; empowered employees and embracing change (see, Table 4). Thus, managers of organizations wishing to implement agile ways of working must express those agile values in their leading and coaching efforts so that they can reduce cultural clashes among their globally distributed IT workers and thereby accomplish a productive agile mindset among them.

Given the great variety of cross-culturally diverse scripts made visible by the very different and sometimes clashing employee behaviors, we suggest that IT companies should only start with transforming to agile when they have managers who are fully aware of their employees' culturally determined scripts. Given today's employees' culturally diverse backgrounds, those managers must then also be able to coach their employees proactively toward making the appropriate adjustments. The above may have illustrated that to become an effectively agile organization or work unit, any given workforce has to embrace not only large structural but also cultural transformations; the transition toward becoming closer to an ideal agile mode of working will only reach its intended purposes if managed very well without underestimations. More research geared at supporting those managers in this complex task is urgently needed.

\section{Notes}

1. Scrum is an agile methodology and a framework to support agile teams to develop, deliver and sustain products: www.scrum.org (Digital.ai ${ }^{\mathrm{TM}}, 2020$ ).

2. During the first year of making the switch to agile, the company Salesforce delivered, amongst others, over $500 \%$ more value to its customers compared to the previous year. " 15 Months after 
JSMA 15,3

adapting Scrum, 86 percent were having a 'good time' or the 'best time' whilst working at the company. Prior to adopting Scrum, only 40 percent had said the same thing. Furthermore, 92 percent of the employees said they would recommend an agile approach to others" (Denning, 2019, p. 6).

3. In managed services, the responsibility of delivering IT and project management work is outsourced to a vendor. In agile-managed services, the nature of the vendor-client partnership changes to a more collaborative agile mode of working.

4. In most Western-managed services contracts, employees are (legally) "transferred" to the vendor. These employees continue to perform the same or similar tasks, but now for their former employer who has become their client. In a country such as the UK, legal regulations preserve the former employees' contractual terms and conditions.

5. The client in this paper is the British firm. The end-user is an employee of the British client, who uses the products and services delivered by the vendor. The word "customer" applies to the consumer of the client's product and/or service.

6. The randomization function in the survey tool presents the values to each respondent in a different order (Roos and Roos, 1977).

7. The agile experts had reached consensus on what they ranked as the most ideal agile work values: (1) transparency; (2) empowered employees and (3) communication; (4) end-user orientation and (5) fast decision-making (see Table 2, last column).

8. Balasubramanian et al. (2017) state that loyalty results in avoiding being direct and forthright. A well-known example is that it is difficult for Indian team members to say "no" and therefore they are likely to use hinting words instead; Westerners need someone to interpret the hinting words (Smite et al., 2020).

9. This means handling social situations so that neither you nor the people you work with feel embarrassed or ashamed by your actions or words (Balasubramaniam et al., 2017).

\section{References}

Achtenhagen, L., Melin, L. and Naldi, L. (2013), "Dynamics of business models - strategizing, critical capabilities and activities for sustained value creation", Long Range Planning, Vol. 46, pp. 427-442, doi: 10.1016/j.lrp.2013.04.002.

Baek, P., Chang, J. and Kim, T. (2019), "Organizational culture now and going forward", Journal of Organizational Change Management, Vol. 32 No. 6, pp. 650-668, doi: 10.1108/JOCM-052018-0121.

Balasubramaniam, B., Cao, L., Kim, J., Mohan, K. and James, T.L. (2017), "Conflicts and complements between eastern cultures and agile methods: an empirical investigation", European Journal of Information Systems, Vol. 26, pp. 206-235, doi: 10.1057/s41303-016-0023-0.

Beck, K., Beedle, M., Van Bennekom, A., Cockburn, A., Cunningham, W., Fowler, M., Grenning, J., Highsmith, J., Hunt, A., Jeffries, J., Kern, J., Marick, B., Martin, R.C., Mellor, S., Schwaber, K., Sutherland, J. and Thomas, D. (2001), "Manifesto for agile software development", available at: http|IIIwww.agilemanifesto.org (accessed 01 December 2020).

Beecham, S., Clear, T., Lal, R. and Noll, J. (2021), "Do scaling agile frameworks address global software development risks? An empirical study", The Journal of Systems and Software, Vol. 171, pp. 1-30, doi: 10.1016/j.jss.2020.110823.

Bianchi, M., Marzi, G. and Guerini, M. (2020), "Agile, stage-gate and their combination: exploring how they relate to performance in software development", Journal of Business Research, Vol. 110, pp. 538-553, doi: 10.1016/j.jbusres.2018.05.003.

Brown, M.E. and Treviňo, L.K. (2009), "Leader-follower values congruence: are socialized charismatic leaders better able to achieve it?”, Journal of Applied Psychology, Vol. 94 No. 2, pp. 478-490, doi: 10.1037/a0014069. 
Cappelli, P., Singh, H., Singh, J.V. and Useem, M. (2010), "Leadership lessons from India”, Harvard Work values of Business Review, March, pp. 1-9.

Chatterjee, S. (2009), "Managerial ethos of the Indian tradition: relevance of a wisdom model", Journal of Indian Business Research, Vol. 1 Nos 2/3, pp. 136-162, doi: 10.1108/ cross-cultural IT workers 17554190911005336.

Conforto, E.C., Salum, F., Amaral, D.C., Da Silva, S.L. and De Almeida, L.F.M. (2014), "Can agile project management be adopted by industries other than software development?", Project Management Journal, Vol. 45 No. 3, pp. 21-34, doi: 10.1002/pmj.21410.

Denning, S. (2018), "Ten agile axioms that make conventional managers anxious", Strategy and Leadership, Vol. 46 No. 5, pp. 10-16, doi: 10.1108/SL-06-2018-0061.

Denning, S. (2019), "Lessons learned from mapping successful and unsuccessful agile transformation journeys", Strategy and Leadership, Vol. 47 No. 4, pp. 3-11, doi: 10.1108/SL04-2019-0052.

Denning, S. (2020), "How the C-suite is embracing agile", Strategy and Leadership, Vol. 48 No. 5, pp. 19-24, doi: 10.1108/SL-06-2020-0084.

Digital.ai $^{\mathrm{TM}}$ (2020), “The 14th annual state of Agile ${ }^{\mathrm{TM}}$ report”, available at: https://stateofagile.com/ home (accessed 02 October 2020).

Dikert, K., Paasivaara, M. and Lassenius, C. (2016), "Challenges and success factors for large-scale Agile transformations: a systematic literature review", The Journal of Systems and Software, Vol. 119, pp. 87-108, doi: 10.1016/j.jss.2016.06.013.

Fagerholm, F. and Pagels, M. (2014), "Examining the structure of lean and agile values among software developers", Agile Processes in Software Engineering and Extreme Programming in Lecture Notes of the 15th International Conference, XP 2014, Rome, Italy, 2014, Vol. 179, Springer, Cham, pp. 218-233, doi: 10.1007/978-3-319-06862-6_15.

Felipe, C.M., Roldán, J.L. and Leal-Rodriguez, A.L. (2017), "The impact of organizational culture values on organizational agility”, Sustainability, Vol. 9 No. 2354, pp. 1-23, doi: 10.3390/su9122354.

Gandomani, T.J. and Nafchi, M.Z. (2016), "Agile transition and adoption human-related challenges and issues: a grounded theory approach", Computers in Human Behavior, Vol. 62, pp. 257-266, doi: 10.1016/j.chb.2016.04.009.

Gewald, H. and Schäfer, L. (2017), "Quo vadis outsourcing? A view from practice", Journal of Global Operations and Strategic Sourcing, Vol. 10 No. 1, pp. 2-17, doi: 10.1108/JGOSS-102016-0031.

Gregory, P., Barroca, L., Sharp, H., Deshpande, A. and Taylor, K. (2016), "The challenges that challenge: engaging with agile practitioners' concerns", Information and Software Technology, Vol. 77, pp. 92-104, doi: 10.1016/j.infsof.2016.04.006.

Gupta, M., George, J.F. and Xia, W. (2019), "Relationships between IT department culture and agile software development practices: an empirical investigation", International Journal of Information Management, Vol. 44, pp. 13-14, doi: 10.1016/j.ijinfomgt.2018.09.006.

Hofstede Insights (2021), "The country comparison tool”, available at: https://www.hofstede-insights. com/country-comparison (accessed 15 March 2021).

Hofstede, G. (1991), Cultures and Organizations: Software of the Mind, McGraw-Hill, New York.

Hoogeboom, M.A.M.G. and Wilderom, C.P.M. (2019), "Advancing the transformational transactional model of effective leadership: integrating two classic leadership models with a video-based method", Journal of Leadership Studies, Vol. 13 No. 2, pp. 23-46, doi: 10.1002/ jls.21655.

Ilmudeen, A., Bao, Y., Alharbi, I.M. and Zubair, N. (2021), "Revisiting dynamic capability for organizations' innovation types: does it matter for organizational performance in China?", European Journal of Innovation Management, Vol. 24 No. 2, pp. 507-532, doi: 10.1108/EJIM-062019-0144. 
JSMA 15,3

Indian Brand Equity Foundation (IBEF) (2021), "IT and BPM industry in India", available at: https:// www.ibef.org/industry/information-technology-india.aspx (accessed 27 November 2021).

Jafari-Sadeghi, V., Amoozad Mahdiraji, H., Busso, D. and Yahiaoui, D. (2022), "Towards agility in international high-tech SMEs: exploring key drivers and main outcomes of dynamic capabilities", Technology Forecasting and Social Change, Vol. 174, pp. 1-13, doi: 10.1016/j. techfore.2021.121272.

Janssen, M. and Van der Voort, H. (2020), "Agile and adaptive governance in crisis response: lessons from the COVID-19 pandemic", International Journal of Information Management, Vol. 55, pp. 1-7, doi: 10.1016/j.ijinfomgt.2020.102180.

Livari, J. and Livari, N. (2011), "The relationship between organizational culture and the deployment of agile methods", Information and Software Technology, Vol. 53, pp. 509-520, doi: 10.1016/j.infsof. 2010.10.008.

Luong, T.T., Sivarajah, U. and Weerakkody, V. (2019), "Do agile managed information systems projects fail due to lack of emotional intelligence?", Information Systems Frontiers, Springer, Vol. 23, pp. 415-433, doi: 10.1007/s10796-019-09962-6 (accessed 05 January 2021).

Magistretti, S., Trabucchi, D., Dell'Era, C. and Buganza, T. (2019), "A new path toward a hybrid model: insights from PwC's Italian experience Centre", Research-Technology Management, Vol. 62 No. 5, pp. 30-37, doi: 10.1108/MD-10-2019-1501.

Mathew, S. and Taylor, G. (2019), "Power distance in India: paternalism, religion and caste: some issues surrounding the implementation of lean production techniques", Cross Cultural and Strategic Management, Vol. 26 No. 1, pp. 2-23, doi: 10.1108/CCSM-02-2018-0035.

Nowak (2020), "Does employee understanding of strategic objectives matter? Effects on culture and performance”, Journal of Strategy and Management, Vol. 13 No. 4, pp. 477-493, doi: 10.1108/ JSMA-02-2020-0027.

O'Reilly, C.A., Chatman, J. and Caldwell, D.F. (1991), "People and organizational culture: a profile comparison approach to assessing person-organization fit", Academy of Management Journal, Vol. 34 No. 3, pp. 487-516, doi: 10.5465/256404.

Paasivaara, M., Behm, B., Lassenius, C. and Hallikainen, M. (2018), "Large-scale agile transformation at Ericsson: a case study", Empiric Software Engineering, Vol. 23, pp. 2550-2596, doi: 10.1007/ s10664-017-9555-8.

Pacheco, G., Van der Westhuizen, D.W., Ghobadian, A., Webber, D.J. and O'Regan, N. (2016), “The changing influence of societal culture on job satisfaction across Europe", British Journal of Management, Vol. 27 No. 3, pp. 606-627, doi: 10.11111/1467-8551.12150.

Pellizzoni, E., Trabucchi, D. and Buganza, T. (2019), "When agility meets open innovation: two approaches to manage inbound projects", Creativity and Innovation Management, Vol. 28 No. 4, pp. 464-476, doi: 10.1111/caim.12337.

Rebentisch, E., Schuh, G., Dölle, C., Mattern, C. and Abel, H. (2018), "Defining Agile culture using topic modelling", Human Behavior and Design proceedings of the 15th International Design Conference DESIGN 2018 in Dubrovnik, Croatia, The Design Society, pp. 2111-2120, doi: 10. 21278/idc.2018.0394.

Rigby, D.K., Sutherland, J. and Noble, A. (2018), "Agile at scale: how to go from a few teams to hundreds", Harvard Business Review, Nos May - June, pp. 88-96.

Roos, L.L., Roos, N.P. and McKinley, B. (1977), "Implementing randomization”, Statistical Science, Vol. 3 No. 4, pp. 547-559.

Schein, E.H. (1985), Organizational Culture and Leadership: A Dynamic View, Jossey-Bass, San Francisco.

Schwartz, S.H., Cieciuch, J., Vecchione, M., Davidov, E., Fisher, R., Beierlein, C., Ramos, A., Verkasalo, M., Lönnqvist, J., Demirutku, K., Dirilen-Gumus, O. and Konty, M. (2012), "Refining the theory of basic individual values", Journal of Personality and Social Psychology, Vol. 103 No. 4, pp. 663-688, doi: 10.1037/a0029393. 
Schwartz, S.H. (1996), "Value priorities and behavior: applying a theory of integrated value systems", in Seligman, C., Olson, J.M. and Zanna, M.P. (Eds), The Psychology of Values, Erlbaum, Mahwah, NJ, Vol. 8, pp. 1-24.

Sharma, S. (2015), "Why Indians work: a cultural values perspective", Indian Journal of Industrial Relations, Vol. 50 No. 3, pp. 425-437.

Šmite, D., Gonzalez-Huerta, J. and Moe, N.B. (2020), "When in Rome, do as the romans do: cultural barriers to being agile in distributed teams", in Stray, V., Hoda, R., Paasivaara, M. and Kruchten, P. (Eds), Agile Processes in Software Engineering and Extreme Programming, Lecture Notes of the 21st International Conference, XP 2020, Copenhagen, Denmark, 2020, Springer, Cham, pp. 145-161, doi: 10.1007/978-3-030-49392-9_10.

Ŝmite, D., Moe, N.B. and Gonzalez-Huerta, J. (2021), "Overcoming cultural barriers to being agile in distributed teams", Information and Software Technology, Vol. 138, pp. 1-16, doi: 10.1016/j. infsof.2021.106612.

Spony, G. (2003), "The development of a work-value model assessing the cumulative impact of individual and cultural differences on managers' work-value systems: empirical evidence from French and British managers", International Journal of Human Resource Management, Vol. 12 No. 4, pp. 658-679, doi: 10.1080/0958519032000057637.

Srinivasan, J. and Lundqvist, K. (2010), “Agile in India: challenges and lessons learned”, ISEC 2010, Proceedings of the 3rd India Software Engineering Conference, pp. 125-130, doi: 10.1145/ 1730874.1730898.

Stray, V., Fægri, T.E. and Moe, N.B. (2016), "Exploring norms in agile software teams", in Abrahamsson, P., Jedlitschka, A., Nguyen Duc, A., Felderer, M., Amasaki, S. and Mikkonen, T. (Eds), Product-Focused Software Process Improvement, PROFES 2016: Lecture Notes in Computer Science, Springer, Cham, Vol. 10027, pp. 458-467.

Taponen, S. and Kauppi, K. (2020), "Service outsourcing decisions: a process framework", Journal of Global Operations and Strategic Sourcing, Vol. 13 No. 2, pp. 171-194, doi: 10.1108/JGOSS-022019-0012.

Teece, D.J. (2007), "Explicating dynamic capabilities: the nature and microfoundations of (sustainable) enterprise performance”, Strategic Management Journal, Vol. 28, pp. 1319-1350, doi: 10.1002/ smj.640.

Thorgren, S. and Caiman, E. (2019), "The role of psychological safety in implementing agile methods across cultures", Research-Technology Management, Vol. 62 No. 2, pp. 31-39, doi: 10.1080/ 08956308.2019.1563436.

Tolfo, C., Wazlawick, R.S., Gomes Ferreira, M.G. and Forcellini, F.A. (2011), "Agile methods and organizational culture: reflections about cultural levels", Journal of Software-Evolution Research and Practice, Vol. 30 No. 9, pp. 1-20, doi: 10.1002/smr.483.

Trabucchi, D., Bellis, P., Di Marco, D., Buganza, T. and Verganti, R. (2020), "Attitude vs involvement: a systematic literature review at the intersection between engagement and innovation", European Journal of Innovation Management, Vol. 24 No. 5, pp. 1730-1762, doi: 10.1108/EJIM-05-2020-0171.

Trompenaars, F. and Hampden-Turner, C. (2012), Riding the Waves of Culture: Understanding Diversity in Global Business, Nicolas Brealey Publishing, London.

Van Dun, D.H. and Wilderom, C.P.M. (2016), "Lean-team effectiveness through leader values and members' informing", International Journal of Operations and Production Management, Vol. 36 No. 11, pp. 1530-1550, doi: 10.1108/IJOPM-06-2015-0338.

Walter, A. (2021), "Organizational agility: ill-defined and somewhat confusing? A systematic literature review and conceptualization”, Management Review Quarterly, Vol. 71, pp. 343-391, doi: 10.1007/ s11301-020-00186-6.

Whitelane Research and PA Consulting Group (2018), "The 2018 UK IT outsourcing study", available at: https://www.paconsulting.com/insights/2018/2018-uk-it-outsourcing-study/ (accessed 01 March 2019). 
JSMA

15,3

376
Xebia (2021), "12.5 years of agile expertise in The Netherlands: trends and next steps for leaders in a changing environment", available at: https://www.agilenxt.com/e-magazine-12.5-year-agile (accessed March 2021).

\section{Corresponding author}

Carla A.J. Bastiaansen can be contacted at: c.a.j.bastiaansen@utwente.nl

For instructions on how to order reprints of this article, please visit our website: www.emeraldgrouppublishing.com/licensing/reprints.htm Or contact us for further details: permissions@emeraldinsight.com 